\title{
The Yukon's experience with COVID-19: Travel restrictions, variants and spread among the unvaccinated
}

\author{
Sara McPhee-Knowles ${ }^{1 *}$, Bryn Hoffman², Lisa Kanary¹
}

\begin{abstract}
The Yukon's experience with coronavirus disease 2019 (COVID-19) has been an interesting one; the territory successfully implemented travel restrictions to limit importing the virus and rolled out vaccines quickly compared to most Canadian jurisdictions. However, the Yukon's first wave of COVID-19 in June and July 2021 overwhelmed the healthcare system due to widespread transmission in unvaccinated children, youth and adults, despite high vaccination uptake overall and mandatory masking. This experience highlights the importance of continued support for public vaccination programs, widespread vaccine uptake in paediatric populations, and the judicious relaxation of non-pharmaceutical interventions in all Canadian jurisdictions as they reopen while more contagious variants emerge.
\end{abstract}

Suggested citation: McPhee-Knowles S, Hoffman B, Kanary L. The Yukon's experience with COVID-19: Travel restrictions, variants and spread among the unvaccinated. Can Commun Dis Rep 2022;48(1):17-21.

https://doi.org/10.14745/ccdr.v48i01a03

Keywords: COVID-19, Yukon Territory, pandemic response, travel restrictions, vaccination, outbreak, northern Canada

\section{Introduction}

The coronavirus disease 2019 (COVID-19) trajectory across Canada has been an uneven one, and the Yukon Territory, Canada is an interesting case. From March 22, 2020, to June 1, 2021, there were 62 cases and two deaths due to COVID-19 in the Yukon (1). An important feature of the Yukon's public health strategy was implementing travel restrictions, where, similar to the Atlantic provinces, travellers entering the territory had to self-isolate for 14 days. The Yukon has a small, sparse population and, thanks to few access points, was able to enforce travel restrictions to limit imported cases. However, in June and July 2021, shortly after lifting some restrictions, the Yukon experienced its first wave of COVID-19 with community transmission, despite having the highest vaccination rate in Canada by the end of May (2). From June 1 to August 2, 2021, Yukon reported 541 new cases of COVID-19 as part of three distinct outbreaks and six deaths in a population of about 42,000 (3). Most people who became ill were unvaccinated (4), with only $14 \%$ of cases fully vaccinated, and none of the COVID-19 patients who died were fully vaccinated (1). On July 28, 2020, the government reported that a total of 52 people were hospitalized during this wave; of that group, 43 were unvaccinated or only partially vaccinated. Fourteen cases, 11 of whom were unvaccinated, were in critical condition and were medically evacuated to larger centers (5). In this commentary, we present the Yukon's experience with the COVID-19 pandemic and highlight lessons learned from its late wave of COVID-19 in June and July 2021.

\section{Background}

The Yukon is Canada's second smallest jurisdiction by population. About $75 \%$ of the population lives in Whitehorse, the territory's capital, and the remainder in 15 smaller communities (3). There are three hospitals. Whitehorse General, the largest, has 56 beds, a range of services including a four-bed intensive care unit, and accommodates 32,000 emergency visits and 3,703 admissions per year. Two community hospitals in Watson Lake and Dawson City have emergency services and six bed inpatient units each, with 112 and 80 admissions per year and 2,627 and 2,812 emergency visits annually, respectively (6). This overall hospital capacity is historically adequate for the population; however, medical evacuation or medical travel is often required for high acuity cases or those requiring specialist care (7). This leaves the Yukon at higher risk during the COVID-19 pandemic, as a significant outbreak could overwhelm healthcare capacity. If cases are also surging in other jurisdictions, medical evacuation to larger centres, such as Vancouver or Edmonton (8), may not be possible. 
Following devolution in 2003, the Yukon territorial government assumed responsibility for public health, along with other provincial powers, from the Canadian federal government. Eleven of the 14 Yukon First Nations are self-governing and able to draw responsibilities from the territorial government, including some related to health, after they pass their own legislation (9). In the 2016 census, approximately $23 \%$ of the population identified as having Indigenous ancestry (10). The Yukon's economy is largely based on government; Yukon depends heavily on federal transfers (11). Mining, services and tourism are also important drivers. Because of self-isolation requirements following travel, tourism decreased by $25 \%$ in the first quarter of 2020 compared to 2019 (12). The unique demographic, economic and institutional context of the Yukon influenced the pandemic response.

\section{Pandemic response}

The Government of Yukon, enabled by its status as a "proto-province" (13), lead the pandemic response; the Council of Yukon First Nations, representing Yukon First Nations governments, also played a role in coordination and communication. Early on, the Yukon government enacted typical public health restrictions such as restricting gatherings, closing bars and personal care services, and suspending healthcare services. The first cases of COVID-19 in Yukon were announced on March 22, 2020 (Figure 1), after restrictions were in place. Restricting out-of-territory travel as of March 22, 2020, limited importing cases into the Yukon: a 14-day self-isolation was required for all travellers entering the territory. Yukoners were requested to limit their rural community travel, and some First Nations governments set up check points into their traditional territories. A border control measures order was issued on April 2, 2020, to enforce self-isolation requirements at border entry points (14). A travel "bubble" with British Columbia was established on July 1, 2020, allowing travel between the two jurisdictions without self-isolation; however, the bubble ended on November 20,2020, after cases began increasing in the Yukon (15). These travel restrictions effectively prevented a major COVID-19 outbreak in the Yukon for the first year of the pandemic. Mandatory masks for Yukoners over the age of five years in public places were instituted on December 1, 2020-one of the last Canadian jurisdictions to mandate mask-wearing (16) since there had been such limited COVID-19 cases present in the Yukon (Figure 1).

The first doses of the Moderna COVID-19 vaccine were administered in Yukon on January 4, 2021, earlier than Canadian provinces because of the territory's limited hospital capacity. Mobile vaccination teams were deployed to communities outside of Whitehorse (17). As of May 22, 2021, 55.22\% of the total population was fully vaccinated (2). Self-isolation requirements were lifted on May 25, 2021 for fully vaccinated domestic travellers, or for fully vaccinated Yukoners returning after domestic travel (Figure 1) (18). This announcement created an additional incentive for vaccination.

Shortly after self-isolation requirements for travellers were lifted, an outbreak of the Gamma variant was declared on June 13, 2021 (Figure 1) (19). Transmission occurred at secondary school graduation parties, bars (20), daycares and the Whitehorse Emergency Shelter; transmission was mostly in unvaccinated adults, youth and children (4). Graduation season facilitated disease transmission because graduates and family members travelled between communities, and attended both informal, unmasked, celebrations and larger, organized gatherings with COVID-19 measures in place. In fact, the outbreak can be linked back to a single infected individual who attended a large party (20). On July 14, 2021, 240 of 414 cases had been confirmed as the Gamma variant (21).

Figure 1: Timeline of key events related to the COVID-19 pandemic in Yukon Territory, Canada from March 1, 2020 to July 31,2021

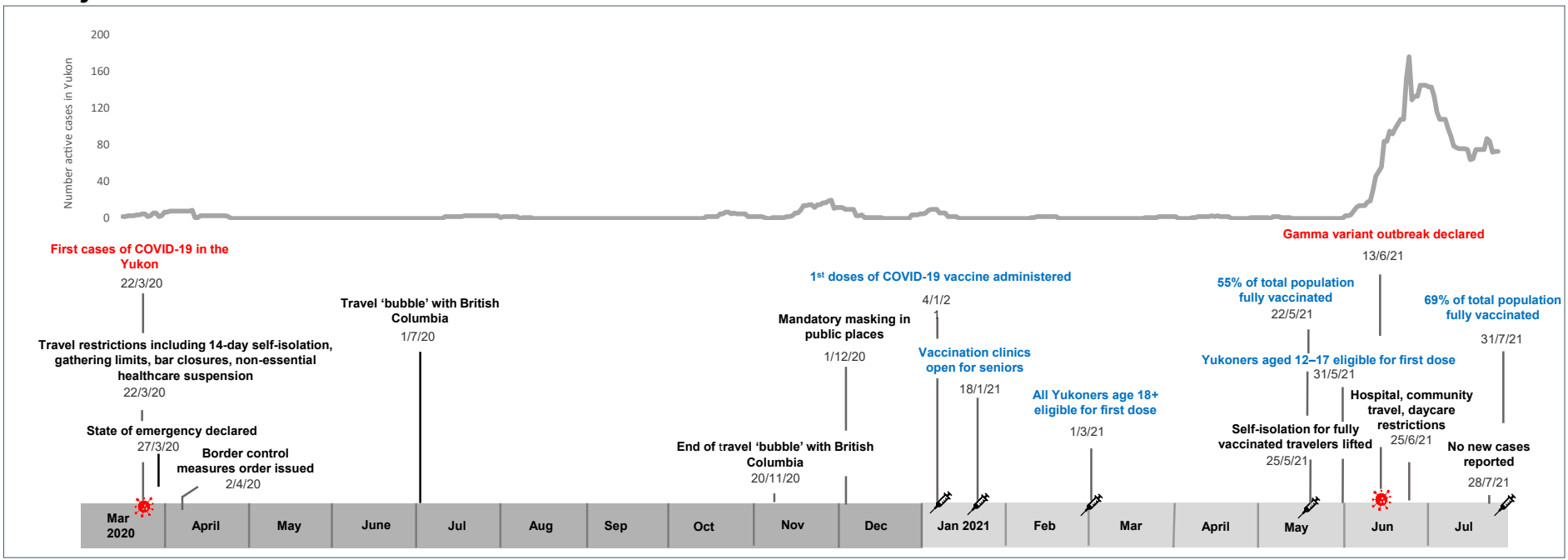

Abbreviation: COVID-19, coronavirus disease 2019 
Yukon's Chief Medical Officer of Health encouraged those not yet vaccinated to book appointments and for all Yukoners to "stick to six" people for gatherings, but lowered formal gathering limits to 10 indoors with masks and 20 outdoors (22). Other public health measures included cancelling some graduation events (23), urging parents to keep children home from daycare (22) and increased restrictions by the Yukon Hospital Corporation (4). Cases were present in most Yukon communities. Many Yukon First Nations requested that travellers refrain from visiting. Contact tracing, testing and vaccination teams were at capacity; the Premier requested additional support from the federal government (22). On July 28, 2021, no new cases were reported for the first time since June 5, 2021; as of July $31,2021,68.63 \%$ of the total population was fully vaccinated (Figure 1) (2). All remaining public health restrictions were lifted on August 4, 2021, including the requirement for travellers who were not vaccinated to self-isolate and mandatory indoor masking (24); this decision received some public criticism, including from the Kwanlin Dün First Nation's chief (25).

\section{Insights}

Some insights can be gleaned from Yukon's experience with COVID-19. The first is the importance of mitigating case importations through self-isolation requirements for travellers entering a region. To illustrate, modeling studies for Newfoundland demonstrated that without introducing a self-isolation requirement for travellers, there would have been 12.4 times more COVID-19 cases in the early weeks of the pandemic (26). Managing case importations is critical in small jurisdictions with limited hospital capacity, such as the Yukon, Northwest Territories and Nunavut. Remote regions may also be able to monitor entry points more easily than larger, better-connected centers. This policy choice meant that the tourism industry was disproportionately affected compared with many other Yukon businesses, and it will not be sustainable in the long-term under these conditions.

A further consideration for the Yukon, and other jurisdictions that did not experience high COVID-19 case counts earlier in the pandemic, was that moving forward with reopening plans meant increasing cases and therefore risk, compared with areas that reopened due to decreasing case counts. There was also a question of timing; reopening shortly before graduation, when there was increased travel between Yukon communities, likely contributed to the rapid outbreak spread.

A central insight, of importance in late 2021 as other Canadian jurisdictions reopened, is that high vaccination rates and mandatory masking were not enough to prevent outbreaks in unvaccinated populations, which put a strain on the local healthcare system. Secondary school students, as part of the
12-17 year age group, were not eligible for vaccination prior to reopening (27), whereas children in daycare were too young to be vaccinated, and some communities had lower vaccination rates than others (28). Policy decisions based on an overall percentage of vaccinated people ignore that unvaccinated groups, because of age or lifestyle, tend to interact, which facilitates disease spread.

Although children do not typically suffer severe illness from COVID-19 (29), daycares were hotspots in Yukon's summer outbreak (22). To manage the outbreak, the Chief Medical Officer of Health recommended that parents who are not essential workers keep their children home if possible. As parents are limited in their ability to work without access to reliable childcare and typically women bear more of the burden for childcare responsibilities, which has been exacerbated by the pandemic (30), this recommendation came with economic consequences that disproportionately impacted women. Currently, children younger than five years of age are ineligible for vaccination and are therefore vulnerable to the more contagious variants of COVID-19.

\section{Conclusion}

A lesson can be taken from the Yukon's experience: travel restrictions in the remote region were effective at mitigating disease importation early during the pandemic, but once these restrictions were removed, the highly contagious Gamma variant circulated in unvaccinated populations. Even with high vaccine uptake and masking, outbreaks occurred that strained public health and healthcare capacity. This is a cautionary tale for other jurisdictions as public health measures are being removed and vaccine uptake has plateaued. Extended COVID-19 disease burden in the Yukon could include unintended consequences, such as more paediatric cases, daycare and school closures and their associated economic and mental health impacts, more difficulties for businesses, and an overburdened healthcare system. These impacts are also being seen elsewhere in Canada during the fourth wave. Widespread vaccination across age groups and communities is needed to reduce the severity of future COVID-19 waves.

\section{Authors' statement}

All authors contributed to conceptualization, writing, as well as review and editing, of this commentary.

The content and view expressed in this article are those of the authors and do not necessarily reflect those of the Government of Canada. 


\section{Competing interests}

None.

\section{Acknowledgements}

The authors would like to thank R Hulstein for his thoughtful comments on an earlier draft.

\section{Funding}

Financial support for this study was provided by the Yukon University Scholarly Activity Grant.

\section{References}

1. Government of Yukon. August 2, 2021: COVID-19 case count update. Whitehorse (YT): Government of Yukon; 2021 (accessed 2021-08-03). https://yukon.ca/en/news/august-22021-covid-19-case-count-update

2. Public Health Agency of Canada. COVID-19 vaccination in Canada. Ottawa (ON): PHAC; 2021 (accessed 2021-08-11). https://health-infobase.canada.ca/covid-19/vaccinationcoverage/

3. Yukon Bureau of Statistics. Population Report, Third Quarter, 2020. Whitehorse (YT): Government of Yukon; 2020. https:// yukon.ca/sites/yukon.ca/files/ybs/populationq3_2020_r_0_0. pdf

4. Government of Yukon. June 27, 2021: New COVID-19 cases confirmed; further guidance on outbreak provided. Whitehorse (YT): Government of Yukon; 2021 (accessed 2021-08-11). https://yukon.ca/en/news/june-27-2021-newcovid-19-cases-confirmed-further-guidance-outbreakprovided

5. Government of Yukon. COVID-19 Facebook live update: July 28, 2021. Whitehorse (YT): Government of Yukon; 2021 (accessed 2021-11-13). https://yukon.ca/sites/yukon.ca/files/ eco/eco-live-update-transcript-july-28-2021.pdf

6. Yukon Hospital Corporation. Our Hospitals. Yukon: YHC; 2021 (accessed 2021-04-29). https://yukonhospitals.ca/ node/251

7. Young TK, Tabish T, Young SK, Healey G. Patient transportation in Canada's northern territories: Patterns, costs and providers' perspectives. Rural Remote Health 2019;19(2):5113. DOl PubMed

8. Cunningham VL. The evolution of the Yukon Medevac Program in an environment of fiscal restraint. CMAJ 1999;161(12):1559-62. PubMed

9. Dacks G. Implementing First Nations Self-Government in Yukon: Lessons for Canada. Can J Polit Sci 2004;37(3):671-94. DOI
10. Anora A. Yukon: Beautiful, Complex, and Changing. Ottawa (ON): StatCan (updated 2021-03). https://www150. statcan.gc.ca/n1/pub/11-631-x/11-631-x2018006-eng.htm

11. Government of Canada. Major federal transfers. Ottawa (ON): Government of Canada; 2014 (accessed 2021-05-01). https://www.canada.ca/en/department-finance/ programs/federal-transfers/major-federal-transfers.html

12. Government of Yukon. Find tourism and visitor statistics and reports. Whitehorse (YT): Government of Yukon; 2019 (accessed 2021-04-29). https://yukon.ca/en/tourismstatistics\#economic-impact-of-tourism-in-yukon

13. Cameron K. Yukon, the 'proto-province': Thoughts on an interesting constitutional parallel. Ottawa (ON): Northern Public Affairs (updated 2016-05-31; accessed 2018-11-08). http://www.northernpublicaffairs.ca/index/yukon-the-protoprovince-thoughts-on-an-interesting-constitutional-parallel/

14. Government of Yukon. A Path Forward: Yukon's Plan for Lifting COVID-19 Restrictions. Whitehorse (YT): Government of Yukon; Mar 2021. https://yukon.ca/sites/yukon.ca/ files/eco/eco-path-forward-yukon-plan-lifting-covid-19restrictions-march-5-2021.pdf

15. d'Entremont D, Howells L. Tears and "divorce": Yukon bursts B.C. travel bubble amid rising COVID-19 cases. CBC News. Nov 19, 2020 (accessed 2021-07-30). https://www. cbc.ca/news/canada/north/yukon-officials-update-isolationrestrictions-tighten-1.5808058

16. Government of Yukon. Wearing a mask in Yukon during COVID-19. Whitehorse (YT): Government of Yukon; 2020 (accessed 2021-07-30). https://yukon.ca/en/health-andwellness/covid-19-information/your-health-covid-19/ wearing-non-medical-mask-yukon

17. d'Entremont D. Here's when and where Yukoners can get vaccinated against COVID-19. CBC News. 2021 (accessed 2021-08-14). https://www.cbc.ca/news/canada/north/yukonofficials-covid-19-update-1.5864875

18. Government of Yukon. Public health restrictions to be lifted on May 25. Whitehorse (YT): Government of Yukon (updated 2021-05-21; accessed 2021-08-11). https://yukon.ca/en/ news/public-health-restrictions-be-lifted-may-25

19. Government of Yukon. Acting Chief Medical Officer of Health declares COVID-19 outbreak. Whitehorse (YT): Government of Yukon; 2021 (accessed 2021-07-31). https:// yukon.ca/en/news/acting-chief-medical-officer-healthdeclares-covid-19-outbreak

20. CBC News. Yukon COVID-19 outbreak linked to single party. CBC; 2021 (accessed 2021-08-11). https://www.cbc.ca/ player/play/1913004611747

21. Government of Yukon. COVID-19 Facebook live update: July 14, 2021 (accessed 2021-11-12). https://yukon.ca/sites/ yukon.ca/files/eco-live-update-transcript-july-14-2021.pdf

22. Government of Yukon. June 30, 2021 COVID-update. YouTube: June 30, 2021 (accessed 2021-08-04). https://www.youtube.com/watch?v=AF99_rcaS2w\&list=PL4 B1jekdBO2rkKxe2fdbOZFlocNRpWZAH\&index=95 
23. Government of Yukon. June 11, 2021: Porter Creek Senior Secondary School prom ceremony cancelled. Whitehorse (YT): Government of Yukon; 2021 (accessed 2021-08-11). https://yukon.ca/en/news/june-11-2021-porter-creek-seniorsecondary-school-prom-ceremony-cancelled

24. Government of Yukon. Additional COVID-19 restrictions to be lifted as vaccine rate increases. Whitehorse (YT): Government of Yukon; 2021 (accessed 2021-07-30). https:// yukon.ca/en/news/additional-covid-19-restrictions-be-liftedvaccine-rate-increases

25. CBC News. Kwanlin Dün pushes back on Yukon reopening plan. CBC; 2021 (accessed 2021-08-11). https://www.cbc. $\mathrm{ca} /$ news/canada/north/kwanlin-d\%C3\%BCn-reopening-toosoon-1.6114522

26. Hurford A, Rahman P, Loredo-Osti JC. Modelling the impact of travel restrictions on COVID-19 cases in Newfoundland and Labrador. R Soc Open Sci 2021;8(6):202266.

DOI PubMed
27. Government of Yukon. COVID-19 vaccination clinics for youth begin May 31. Whitehorse (YT): Government of Yukon; 2021 (accessed 2021-08-12). https://yukon.ca/en/news/ covid-19-vaccination-clinics-youth-begin-may-31

28. Government of Yukon. Sleeves up, Yukon. The future is looking bright. Whitehorse (YT): Government of Yukon; 2021 (accessed 2021-04-30). https://yukon.ca/this-is-ourshot\#vaccine-progress-in-yukon

29. Cui X, Zhao Z, Zhang T, Guo W, Guo W, Zheng J, Zhang J, Dong C, Na R, Zheng L, Li W, Liu Z, Ma J, Wang J, He S, Xu Y, Si P, Shen Y, Cai C. A systematic review and meta-analysis of children with coronavirus disease 2019 (COVID-19). J Med Virol 2021;93(2):1057-69. DOI PubMed

30. Power K. The COVID-19 pandemic has increased the care burden of women and families. Sustain Sci Pract Policy. 2020;16(1):67-73. DOI

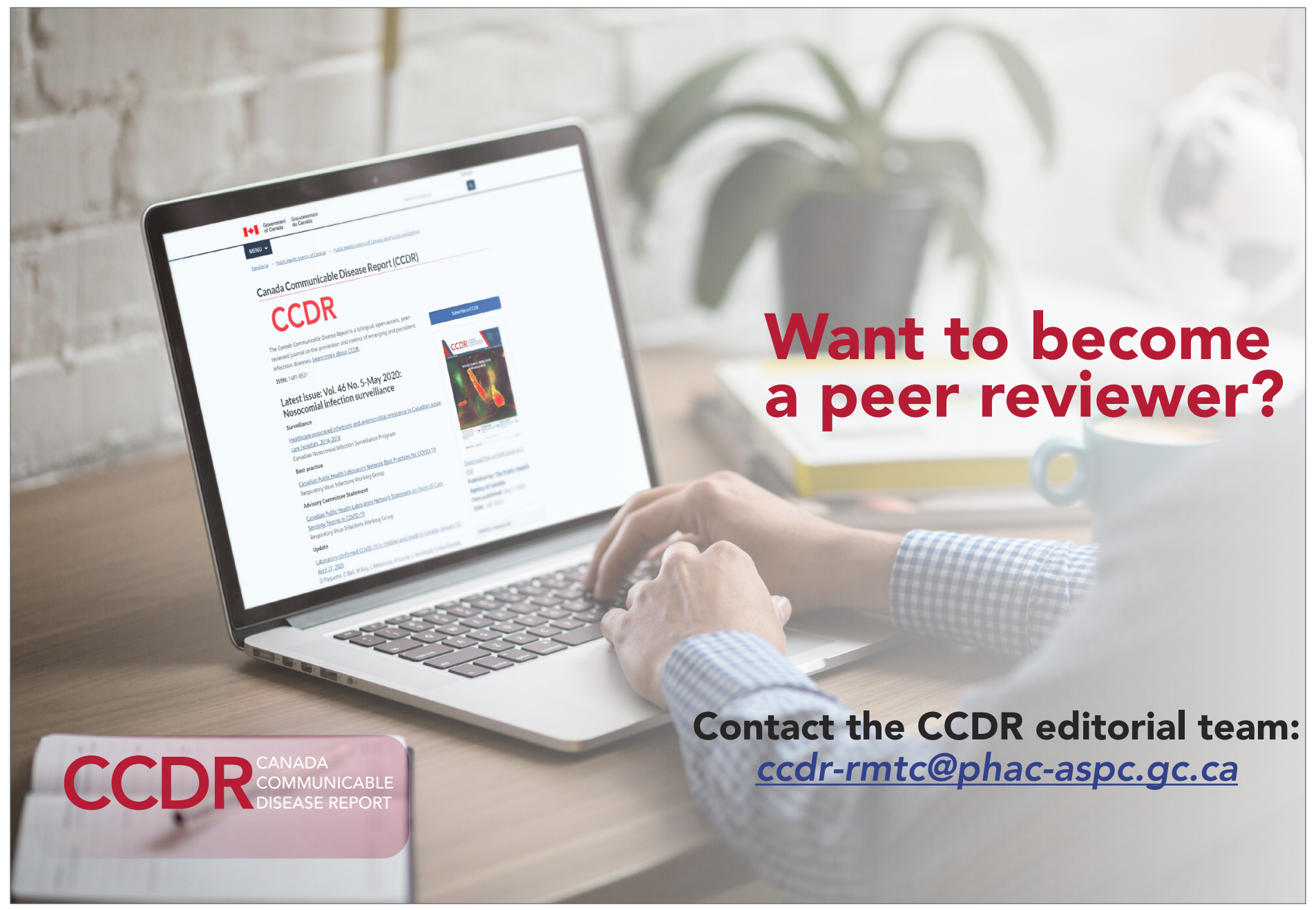

